\title{
Evaluation of environmental sensitivity of the marine regions
}

\author{
M. IOSJPE* and A. LILAND \\ Norwegian Radiation Protection Authority - Grini næringspark 13 \\ 1332 Østerås, Norway
}

\section{Introduction}

The term "environmental sensitivity of marine regions" describes the vulnerability of different marine areas to harmful effects of radionuclide releases. This is intuitively understood, however, it is not easy to find a clear definition of the term that is suitable for modeling. It is necessary to give some consideration to the different elements of the marine environment, including: (i) the water and sediment phases and their interactions and (ii) different pathways and bioaccumulation processes of the marine organisms for the different radionuclides. Furthermore, one must define what endpoint(s) is of concern (doses to humans, marine organisms, etc.).

The present study will provide a sensitivity analysis of different endpoints, based on a study of the radioecological consequences after a hypothetical accident scenario for a modern Russian nuclear submarine, where a wide set of radionuclides is released into the marine environment.

\section{Methodology}

This study consists of three parts: (i) the implementation of the radionuclide source term, (ii) application of a relevant dispersion model for assessing the

\footnotetext{
${ }^{*}$ E-mail: Mikhail.Iosjpe@nrpa.no
}

This is an Open Access article distributed under the terms of the Creative Commons Attribution License 2.0, which permits unrestricted use, distribution, and reproduction in any medium, provided the original work is properly cited. 
doses to humans and biota, with different methodological approaches for each and (iii) the carrying out of the environmental sensitivity analysis.

\subsection{Accident scenario}

The accident scenario has been developed on the basis of the latest results from studies on submarine reactors, fuel design and the operational parameters of a modern Russian vessel (third-generation submarine). Only one of the prepared accident scenarios will be discussed in the present paper and used for the following calculations. The detailed description of the methodology used during the preparation of the accident scenarios can be found in (Reistad, 2008). In total, 110 radionuclides have been considered and 73 of them have been included in the following investigation. The accident location has been selected as the Southern-West part of the Barents Sea in accordance with probable sailing routes leading from the main Russian submarine bases to the Atlantic Ocean.

\subsection{Brief description of the NRPA box model}

The box model developed at NRPA uses a modified approach for compartmental modeling (Iosjpe et al., 2002) which allows for dispersion of radionuclides over time. The box model includes the processes of advection of radioactivity between compartments, sedimentation, diffusion of radioactivity through pore water in sediments, resuspension, mixing due to bioturbation, particle mixing and a burial process for radionuclides in deep sediment layers. Radioactive decay is calculated for all compartments. The contamination of biota is further calculated from the known radionuclide concentrations in filtered seawater in the different water regions. Doses to man are calculated on the basis of seafood consumptions, in accordance with available data for seafood catches and assumptions about human diet in the respective areas. Dose rates to biota are developed on the basis of calculated radionuclide concentrations in marine organisms, water and sediment, using dose conversion factors.

It is important to note that the concentration factors used for calculating dose rates to biota can differ significantly from IAEA recommendations. This is largely because concentration factors given in ERICA data base are calculated for the whole organism, whereas IAEA concentration factors are often defined only for edible parts of the organism i.e., that which has a potential consequence for dose assessments to man. In the present report, dose rates to man were calculated on the basis of concentration factors from 
the IAEA recommendations. For the calculations of dose rates to biota a conservative approach was chosen using concentration factors from the ERICA database, when these concentration factors were higher than the corresponding concentration factors from IAEA recommendations.

\subsection{Sensitivity indexes}

The radioecological consequences after the release of radionuclides into the marine environment have been described in the present study with the help of the following state parameters: concentrations of radionuclides in typical seafood, collective dose rates to man, individual doses for the critical group, and doses to marine organisms. Simultaneously, these state parameters have been considered as the endpoints for the sensitivity analysis with the following sensitivity index: $\mathrm{SI}_{\mathrm{SP}}=\frac{\mathrm{SP}_{\max }}{\mathrm{R}_{\mathrm{SP}}}$, where $\mathrm{SP}_{\max }$ is a maximum value of the state parameter $\mathrm{SP}$ for the present scenario and $\mathrm{R}_{\mathrm{SP}}$ is a maximum value of parameter SP according to the existing recommendations and criterions for protection of the human population and the environment.

According to the present formulation of the sensitivity index, when $\mathrm{SI}_{\mathrm{SP}}<1$ the radioecological consequences to humans and the environment are considered non-harmful with regards to the given parameter (in this case, SP). Thus, the use of this index allows for easy qualitative analysis for any endpoint.

\section{Results and discussion}

\subsection{Concentration of radionuclides in seafood}

The Food and Agriculture organization of the United Nations and World Health Organization have provided recommendations (guideline levels) for the maximum permissible concentration of radionuclides in foods, when contaminated after an accidental release of radionuclides. According to the Codex Alimentarius Commission (CAC, 2006) radionuclides can be separated into four groups. Corresponding calculations of the sensitivity indexes have been performed separately for each of these groups of radionuclides.

Mainly, the evaluated sensitivity indexes for the concentration of radionuclides in seafood have been substantially below 1. At the same time, two of the sensitivity indexes in the zone closest to the accident location: $\mathrm{SI}_{\mathrm{C}_{\mathrm{MOL}}^{(\mathrm{GR} 2)}}$ for the concentration of group 2 radionuclides in mollusks and $\mathrm{SI}_{\mathrm{C}_{\mathrm{BENTHIC} \text { (GRISH }}^{\text {(GR3) }}}$ for concentrations of group 3 radionuclides in benthic fish, 


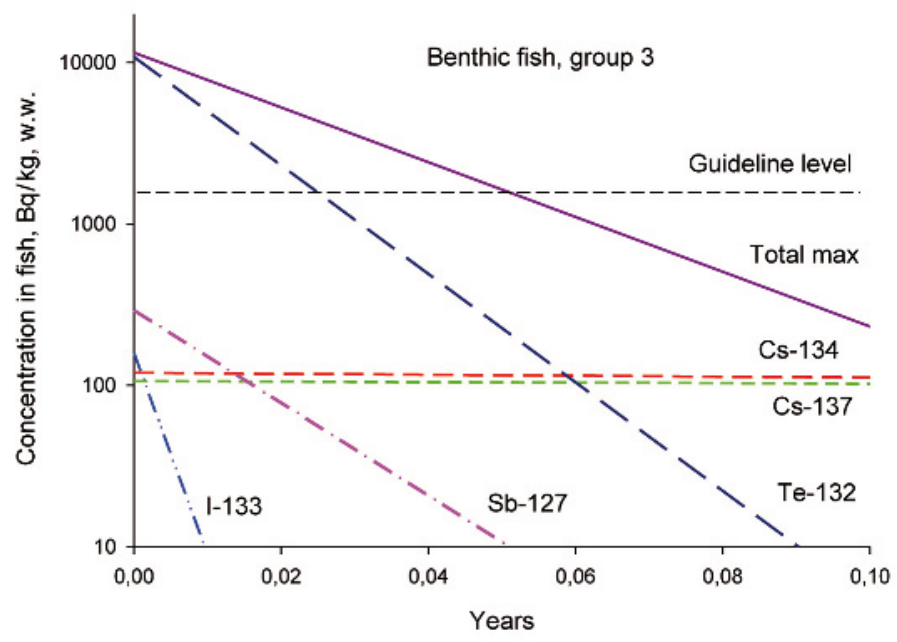

Figure 1: Concentration of radionuclides (Group 3) in benthic fish in the bottom waters near the accident location.

significantly exceed the non harmful level during the initial time of the radionuclide release: $\mathrm{SI}_{\mathrm{C}_{\mathrm{MOL}}^{(\mathrm{GR} 2)}}=2.5$ and $\mathrm{SI}_{\mathrm{C}_{\mathrm{BENTHIC} \text {.FISH }}^{(\mathrm{GR} 3)}}=11.5$ (Figure 1 shows results for the group 3 radionuclides in benthic fish).

\subsection{Collective dose-rates to man}

More than 50 radionuclides were considered; Figure 2 presents the results for the radionuclides that were calculated to have the most significant impact regarding doses to man during the initial period of release.

The exposure rates in the range of $1-10 \mu \mathrm{Sv}$ per year constitutes, according to (UNSCEAR, 2000), a negligible component of the annual effective dose from natural sources. A rough estimation of the population, which will be affected during the first two years after accident, is $1.4 \cdot 10^{7}$. With this assumption, the value $1 \mu \mathrm{Sv} \cdot \times 1.4 \cdot 10^{7}=14$ man Sv per year can be used as conservative estimation of the negligible component of the annual effective dose from natural sources. Simultaneously, this negligible component of the annual effective dose from natural sources can be used as a parameter $R_{C D}$ in a sensitivity analysis where the endpoint is the collective dose rate CD. Thus, the sensitivity index for the collective dose rate can be written as $\mathrm{SI}_{\mathrm{CD}}=\frac{\{\mathrm{CD}\}_{\max }}{\mathrm{R}_{\mathrm{CD}}}=14 \operatorname{man} \mathrm{Sv} / 14 \operatorname{man} \mathrm{Sv}=1$. 


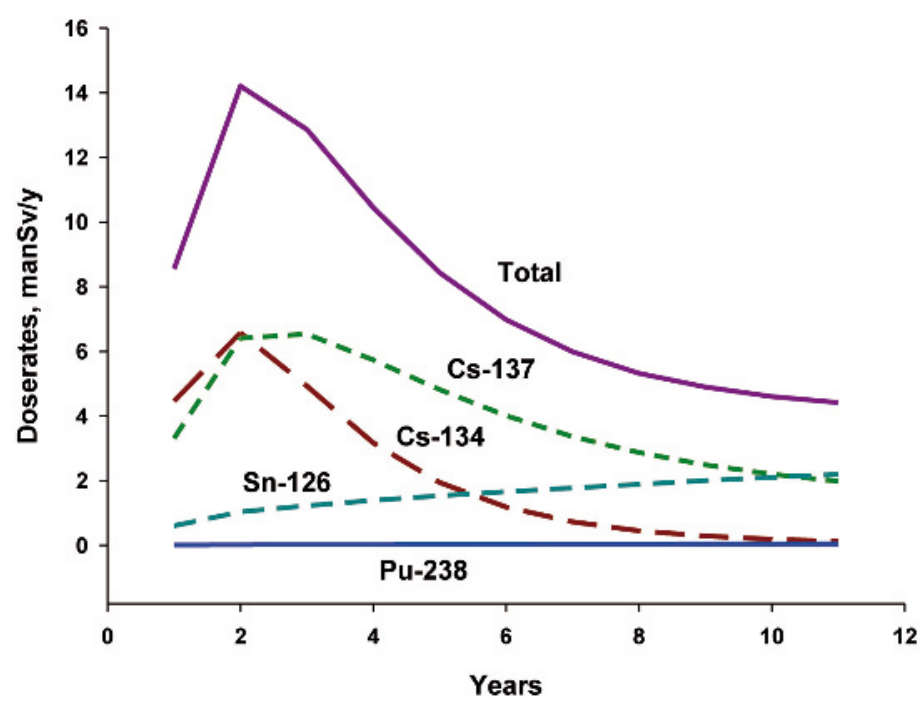

Figure 2: Collective dose-rates.

\subsection{Doses to the critical group}

According to an investigation of consumption patterns for different populations living on the Norwegian coast and inland, maximum seafood consumption is 200, 40 and $4 \mathrm{~g} \mathrm{day}^{-1}$ for fish, crustaceans and mollusks, respectively. Based on this investigation, the hypothetical group with heavy consumption of seafood from the most affected sea region (the southern part of the Barents Sea) was chosen for the evaluation.

The calculated maximal dose-rate equals $82 \mu \mathrm{Sv} \mathrm{yr}^{-1}$. Similar to the section 3.2 , the dose rate of $1 \mu \mathrm{Sv} \mathrm{yr}^{-1}$ can be considered as a negligible component to the annual individual dose from natural sources (UNSCEAR, 2000) and, therefore, can be used as a parameter $R_{\text {CGD }}$ in a sensitivity analysis where the endpoint is the dose rate to the critical group CGD.

The sensitivity index for the dose rate to the critical group can be expressed as

$$
\mathrm{SI}_{\mathrm{CGD}}=\frac{\{\mathrm{CGD}\}_{\max }}{\mathrm{R}_{\mathrm{CGD}}}=82 \mu \mathrm{Sv} / 1 \mu \mathrm{Sv}=82 .
$$

\subsection{Doses to marine organisms}

It has previously been suggested that the screening dose rate of $10 \mu \mathrm{Gy} \mathrm{h}^{-1}$ or less are not harmful to marine biota (Brown et al., 2006). On the other 
Table 1: The sensitivity indexes for biota dose rates.

\begin{tabular}{|l|c|c|c|}
\hline & Fish & Crustaceans & Molluscs \\
\hline Individual level & 0.3 & 0.4 & 0.6 \\
\hline Population level & 0.009 & 0.01 & 0.014 \\
\hline
\end{tabular}

hand, according to the US Department of Energy, the dose rate limit of $400 \mu \mathrm{Gy} \mathrm{h}^{-1}$ can be accepted for native aquatic animals (US DoE, 2002). This difference can primarily be explained by the different approaches for evaluating these dose rate limits. The estimation of the screening dose rate is based on the evaluation of radiation effects to individual organisms, while the dose rate limit, provided by US DoE (2002), is based on the evaluation of effects for the population of aquatic organisms, where minor effects for individual organisms are not expected to be significant for the viability of the population.

The screening dose rate of $10 \mu \mathrm{Gyh}^{-1}$ and the dose rate limit of $400 \mu \mathrm{Gy} \mathrm{h}^{-1}$ can be used as parameters $\mathrm{R}_{\mathrm{DB}}$ and $\mathrm{R}_{\mathrm{DBP}}$ in a sensitivity analysis where the endpoints are the doses to biota (individual and population level, respectively).

The sensitivity indexes for the biota dose rates for both individual and population levels are presented in Table 1.

Results in Table 1 indicate that the sensitivity indexes for biota dose rates are below 1 (significantly so for the population level). However, both sensitivity indexes $\mathrm{SI}_{\mathrm{DB}}$ and $\mathrm{SI}_{\mathrm{DBP}}$ for individual and population levels, respectively, are significantly higher than 1 for the polychaete worm, living in the sea sediment (the dose rate dynamic for the polychaete worm is shown in Figure 3): $\mathrm{SI}_{\mathrm{DB}}=108$; and $\mathrm{SI}_{\mathrm{DBP}}=2.7$. It is important to note that, because the lifespan of the polychaete worm is only 2-3 years, these potentially harmful conditions may last for several generations.

\section{Conclusions}

A sensitivity analysis of different endpoints, based on a study of the radioecological consequences after a hypothetical accident scenario for a modern Russian nuclear submarine was performed.

The following state parameters were selected as endpoints: concentrations of radionuclides in typical seafood, collective dose rates to man, individual doses for the critical group and doses to marine organisms.

The results show that the doses to marine organisms living in the sea sed- 


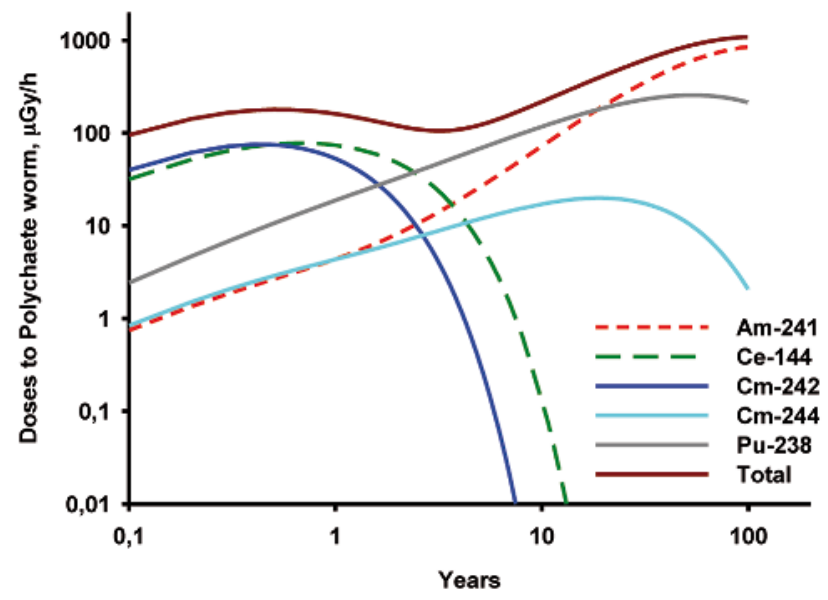

Figure 3: Doses to the Polychaete Worm.

iment near the accident location, and dose rates to the critical group are the most sensitive state parameters (endpoints) for describing the consequences to the marine environment in the present evaluation.

The sensitivity analysis also shows that the concentration of radionuclides in some seafood products (produced from marine organisms near the accident location) would be in excess of WHO recommendations during the initial time of release.

Knowing that the most vulnerable endpoint for the human population is the dose rate to the critical group allows for the development of proper response strategies to similar accidents. For example, restricting the catchment of seafood from the marine area near the accident location during the initial time of radionuclide release will significantly decrease the doses to the critical group. In addition, one should consider the potential harm to certain marine organisms living in the sediment, particularly those with short generation-spans.

\section{Acknowledgements}

The authors wish to thank Dr. Ole Reistad at NRPA for assistance in calculating the release inventories and Dr. Bliss L. Tracy, Dr. Luigi Monte, Prof. Franca Carini and Dr. John E. Brittain (the EMRAS II programme, Sensitivity Environment Group) for their participation in constructive discussions. 
The study was financed by the Norwegian Ministry of Foreign Affairs through its Action Plan for Nuclear Safety

\section{References}

Brown, J.E., A. Hosseini, P. Børretzen \& H. Thørring, Development of a methodology for assessing the environmental impact of radioactivity in Northern Marine environments, Mar. Pollut. Bull., 52, no. 10 (2006) 11271137.

CAC, 2006. Codex Alimentarius Commission: Joint FAO/WHO Food Standards Programme. Appendix 31. ftp://ftp.fao.org/codex/Alinorm06/ al29_41e.pdf (09.01.07).

Iosjpe, M., J. Brown \& P. Strand, Modified approach for box modeling of radiological consequences from releases into marine environment, J. Environ. Radioact., 60 (2002) 91-103.

Reistad O., Analyzing Russian naval nuclear safety and security by measuring and modeling reactor and fuel inventory and accidental releases, Doctoral thesis at NTNU, 14 (2008).

US DoE, A graded approach for evaluation radiation doses to aquatic and terrestrial biota. Technical Standard DoE-STD-1153-2002 (Washington, DC, USA) 2002.

UNSCEAR, Sources and effects of ionizing radiation. UNSCEAR 2000 Report to the General Assembly with Scientific Annexes. Volume I: Sources (UN, New York) 2000. 